\title{
Design and Modeling of Speed Sensorless Control of DC Motor Drive System
}

\author{
Ahmed A. Allu \\ Lecturer, Technical Institute/Mosul
}

\author{
Dr. Rakan K. Antar \\ Lecturer, Technical College/Mosul
}

\begin{abstract}
Sensorless speed control of a separately excited DC motor using Artificial Neural Network (ANN) technique based on current sensor alone is applied in this paper. The speed sensorless system based on ANN is estimated adaptively to overcoming mechanical and physical problems associated with traditional speed sensor. The power circuit of the DC drive system consists of four-quadrant DC chopper with MOSFET transistors and reverse diodes. The ANN is trained, as a model adaptive reference system method, to estimate speed of the DC motor based on armature current sensor of the drive circuit and reconstructed terminal voltage waveform, which is generate depending on the PWM pulses of the DC chopper, as ANN inputs. The DC drive controller consists of proportional-integral controller, logic gates and routing circuits beside the trained ANN. The DC drive circuit is designed, evaluated and modelled by Matlab/Simulink in the forward and reverse motoring operation modes, respectively. The DC drive system is simulated at different speed variation in steady state and dynamic operating conditions. The simulation results without speed sensor illustrate the effectiveness and successful of the control system, fairly good response and acceptable agreement between the actual, estimated and desired speeds.
\end{abstract}

Keywords: DC motor control, neural network technique, sensorless speed control.

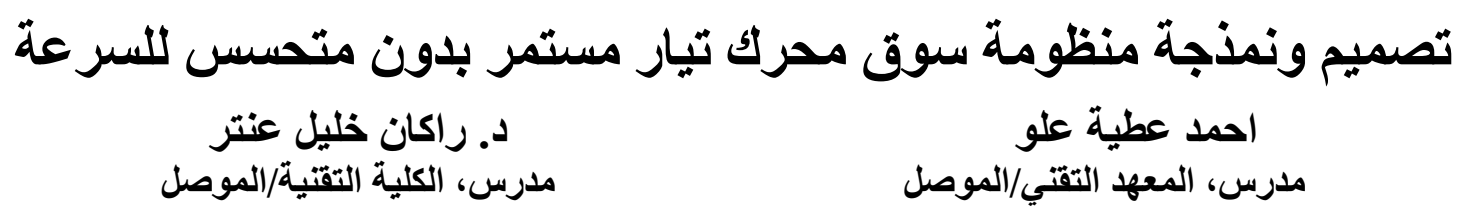

الخلاصة

تم في هذا البحث الاستفادة من تقنية الثبكة العصبية الاصطناعية مع متحسس التيار لسوق محرك تبكار التبار مستمر منفصل

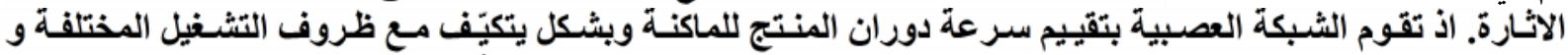

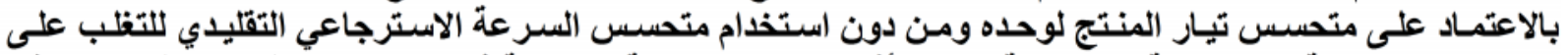

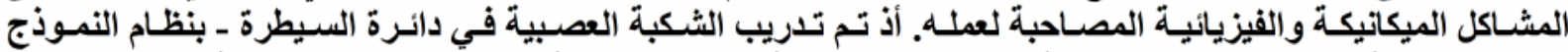

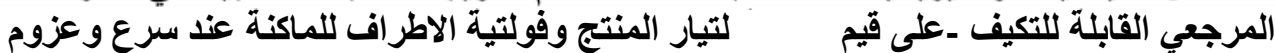

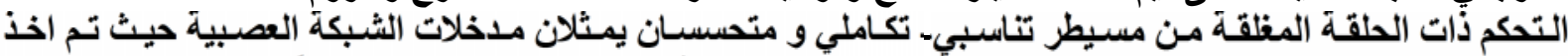

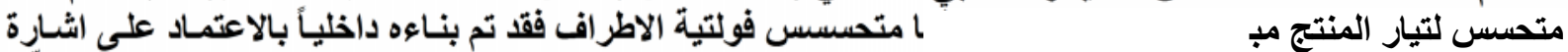

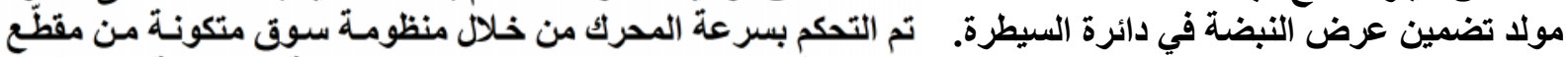

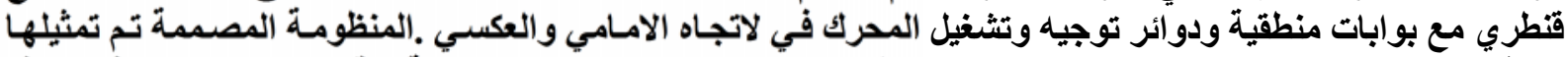

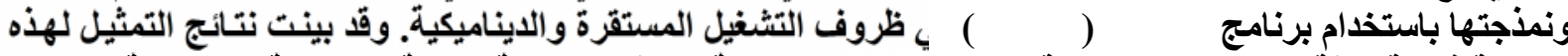
الطريقة فعالية ودقة السيطرة والاستجابة الجيدة من خلال المقارنة بين قيم السرعة الفعلية والمخمنة والمبلة والمطلوبة. 


\section{Introduction}

DC motors are usually used in industrial applications due to their high reliabilities, flexibilities and low costs. Speed control of a separately excited DC motor has been studied since the early decades in the last century [1]. The precise speed control of a DC motor is required in some applications. In this situation, speed sensor feedback is used [2]. Speed data is gotten depending on tachometer or speed transducer on the motor shaft, which may have an effect on the mechanical robustness of the DC drive. In addition, the closed loop system stability is affected with changing of speed sensor characteristics [3]. To avoid speed sensor problems, sensorless speed control of a DC motor drive is used in this paper. The performance of a DC drive also depends on the static power converter's performance.

Different techniques are used to control speed of DC motors depending on proportional-integral-derivative (PID) controller, adaptive system, state space control, artificial neural network (ANN), fuzzy logic, etc [4-6]. In this paper, the sensorless speed control of a separately excited DC motor is done using ANN, which is trained to estimate the motor speed depending on instantaneous armature current of the DC chopper as shown in Figure (1).

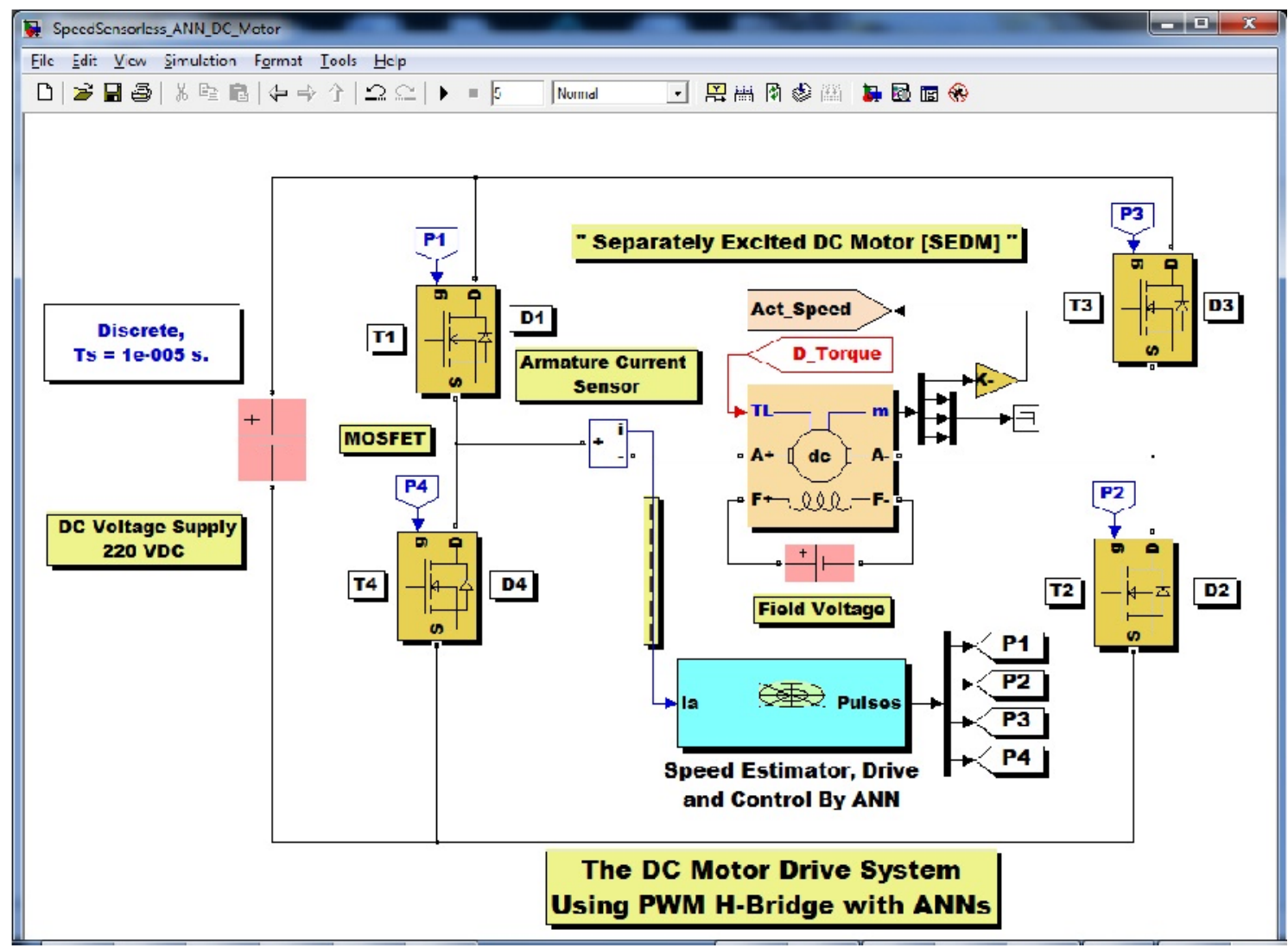

Figure (1): The proposed power circuit of the DC/DC H-bridge chopper.

\section{The H-bridge Chopper Fed a Separately Excited DC Machine}

In order to drive a separately excited DC motor in the forward and reverse motoring modes, a four-quadrant H-bridge PWM DC/DC chopper is used as shown in Figure (1). The converter circuit supplied from a DC source consists of four MOSFET transistors $(\mathrm{T} 1, \mathrm{~T} 2, \mathrm{~T} 3, \mathrm{~T} 4)$ with freewheeling diodes (D1, D2, D3, D4) as a power electronics switching 
devices of the H-bridge DC chopper circuit. These devices are controlled according to the PWM pulse signals (P1, P2, P3, P4).

In order to drive the DC motor in the forward motoring mode, transistors T1 and T2 are controlled and transistors T3 and T4 are switched off. If both T1 and T2 are turning on, the supply voltage appears across the motor terminals and the armature current will rise. While if T1 is switched off and T2 stilled turn on, the armature current decays through D4. While in the reverse motoring mode, transistors T3 and T4 are controlled. On the contrary, T1 and T2 are switched-off. If transistors T3 and T4 are turn on together, the armature current will rise and flow in reverse direction. But if transistor T3 is switched-off and T4 is turned-on, the armature current will fall through T4 and D2 [7].

\section{Modelling of Sensorless Speed Control}

The machine speed is controlled by controlling the DC output of the H-bridge chopper. The estimation speed of the DC motor is calculated from the instantaneous armature current and reconstructed terminal voltage waveform, which is produce depending on the PWM pulses of the DC chopper as illustrated in Figure (2). ANN is used to achieve sensorless speed control. The trained ANN has two inputs (armature current and reconstructed terminal voltage signals) to produce the estimation speed of the DC motor (sensorless speed). The DC motor speed is controlled with varying terminal voltage which it is employed by switching frequency $(5 \mathrm{kHz})$ of Pulse Width Modulation (PWM) and tuned through duty cycle $(\mathrm{K})$, In this work, the voltage sensor $\left(V_{t}\right)$ is reconstructed internally depend on duty cycle of the PWM generator signals, which is used to drive the chopper circuit. By assuming the voltage source is constant, the reconstructed DC voltage is determined as:

$$
\mathrm{V}_{\mathrm{t}-\text { reconstructed }}=\mathrm{K} . \mathrm{V}_{\mathrm{s}}
$$

The only DC-link measurement is armature current sensor, which can be written using Laplace's Transform as [5, 6]:

$$
\mathbf{I}_{\mathbf{a}}(\mathbf{s})=\frac{\mathrm{Vt}-\text { reconstructed }(s)-\mathrm{Ke}(\mathrm{s}) \cdot \frac{2 \pi n}{60}}{(\mathrm{sLa}+\mathrm{Ra})}
$$

Where $R_{a}$ and $L_{a}$ are armature resistance and inductance, $n$ is the motor speed,

$K_{e}$ is a machine constant and calculated from $\left(L_{a f} * I_{f}\right)$ and $\left(L_{a f}\right)$ is a mutual inductance between armature and field coils. The field current of separately excited machine is calculated as [5, 6]:

$\mathbf{I}_{\mathbf{f}}(\mathbf{s})=\frac{\mathrm{V} f(s)}{(\mathrm{sLf}+\mathrm{Rf})}$

Where $R_{f}$ and $L_{f}$ are field resistance and inductance. The estimated rotor speed of motor is compared with the reference speed and the resultant, which is the error signal, is sent to a Proportional-integral (PI) controller as shown in Figure (2). The PI controller gains value are tuned by trial and error process with $\left(\mathrm{K}_{\mathrm{P}}=3.15, \mathrm{~K}_{\mathrm{i}}=171\right)$, respectively. The output of the PI controller is the modulation index value. It is compared with the carrier signal to produce the required PWM patterns of the H-bridge chopper in order to drive the DC motor in the forward and reverse direction for motoring and regenerative braking operation modes. The mode of operation is selected by comparators which are employed as logical switches to pilot PWM signals to driver logical gates properly. The designed controller has outstanding speed response for different load torques and gets steady state as quick as possible.

The closed loop speed controller of the DC machine is composed of ANN for rotor speed estimation as a Model Reference Adaptive System (MRAS). In this research, the 
trained ANN has three neuron layers. The output layer neurons, which are supervised backpropagation method, have a linear transfer function. The hidden layer neurons have logsigmoid transfer function and (35) neurons. The ANN connective weights are trained off-line according to large data with error bounded equal to $1 \mathrm{e}-5$. The load torque of the DC motor is dynamically changed between $+\mathrm{TL}$ and -TL according to the required speed and power directions to run the machine in the forward and reverse modes.

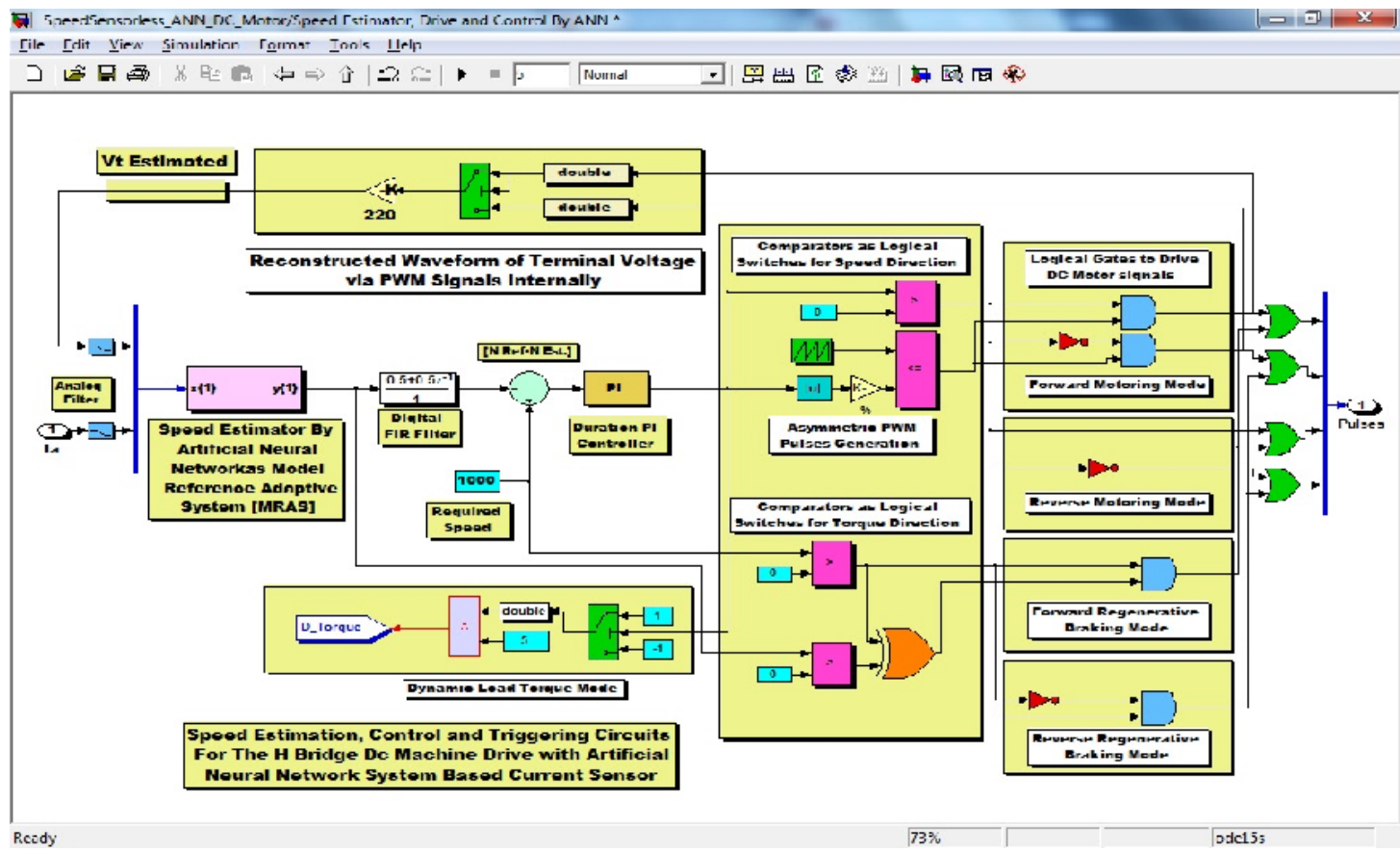

Figure (2): Modelling circuit of the sensorless speed controller.

\section{Analogue and Digital Filters with ANN}

In this paper, analogue and digital filters with ANN have been applied successfully to enhance the performance of the DC drive circuit and its control circuit. Switching operation of the DC chopper devices causes distortion in the voltage and current waveforms, which gives slow and oscillated response for the estimated speed of DC motor. Subsequently, the ANN recognition for motor speed will suffer from oscillation in its values caused by higher order harmonics. To overcome this problem, analogue and digital filter are used with the inputs and outputs of the trained ANN. The analogue low pass filters, with $2^{\text {nd }}$ order and high cut-off frequency ( $200 \mathrm{~Hz}$ ), are used to minimize such anti-aliasing effect as well as attenuate the high frequency components of $\left(V_{t}\right)$ and $\left(I_{a}\right)$. The digital finite impulse response filter is used to improve the numerical algorithm (ANN pattern recognition). The FIR filter-Direct form has numerator coefficients [0.5 0.5$]$ and sampling time (Ts) equal to $1 \mathrm{e}-5$ second.

\section{Simulation Results}

To estimate the dynamic performance of the DC drive system under different speed and load torque conditions, simulation of DC motor has been done. The dynamic speed, average terminal voltage $\left(V_{t}\right)$ and armature current $\left(I_{a}\right)$ responses of the DC motor drive system in the forward motoring mode at load torque (TL) equalling to $(5 \mathrm{~N} . \mathrm{m})$ are shown in Figure (3). The estimated and actual speeds are matched, stabled and reached the reference speed within 0.6 second. The estimated (sensorless) and actual speeds have good response. The average terminal voltage $\left(V_{t}\right)$ waveform has a good response, while the armature current gets steady-state with a certain overshoot due to nature of the sensorless controller system. 
Figure (4) shows the dynamic speed, average terminal voltage and armature current responses of the DC motor drive system in the reverse motoring mode at load torque (TL) equalling to $(-5 \mathrm{~N} . \mathrm{m})$. The speed responses are matched and arrived the reference speed within 0.5 second. The average terminal voltage has a good response. The response of the armature current has overshoot at speed changing point due to nature of the sensorless controller system.

The sensorless system controller controls the DC motor in the forward and reverse motoring modes simultaneously as shown in Figure (5) and Figure (6). These figures illustrated the dynamic speed, average terminal voltage and armature current responses.

Figures (7), (8), (9), and (10) explain the effectiveness of the system controller ability to control the DC motor in the forward and reverse modes at certain speed and different load torque. These figures illustrated that the speed response stay around the reference speed (1000rpm) with steady state error around zero. The sensorless speed tracks the reference value and gives a good response as confirmed by the actual values. Also the terminal voltage and armature current responses arrive the steady-state point. These figures explain the capability of the DC H-bridge chopper to run the DC motor in the forward and reverse motoring modes.

The overall sensorless speed response of the DC motor is good compared with the actual value which proves the effectiveness of the sensorless control system to track the required speed and load torque.

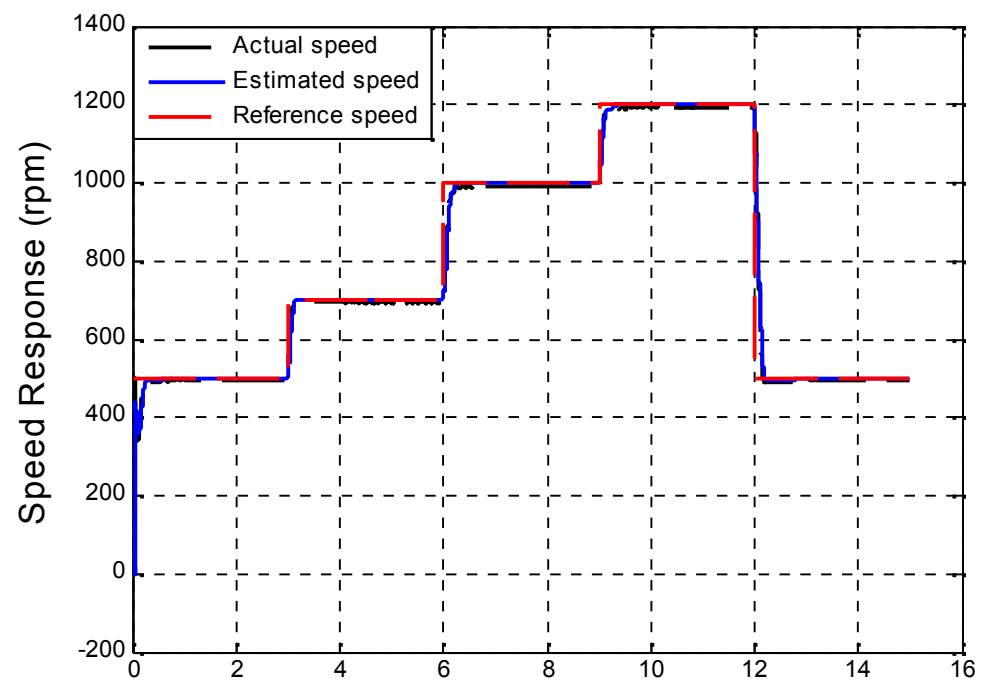

(a)

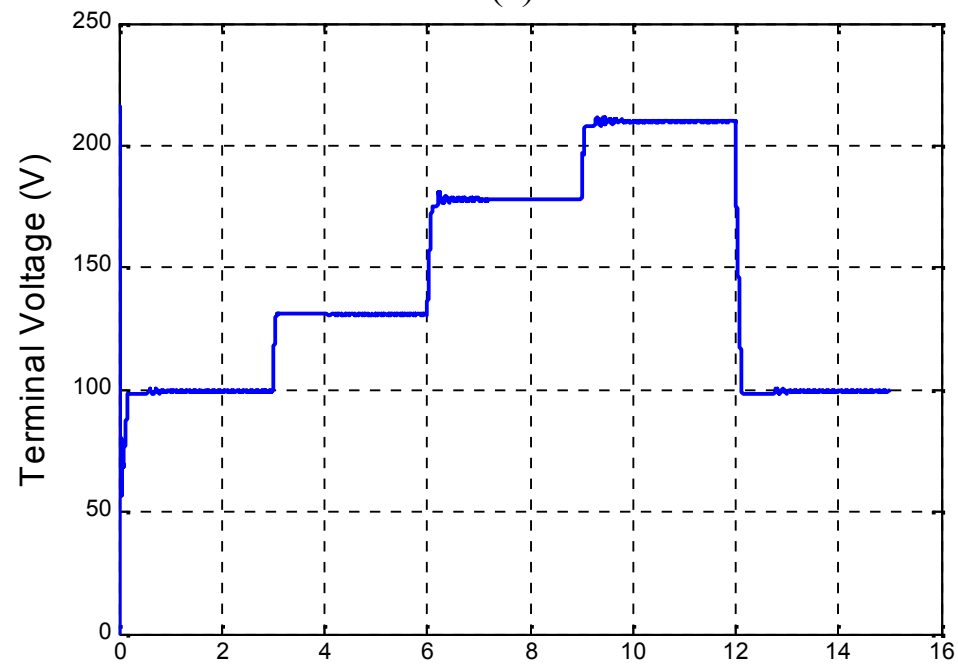

(b) 


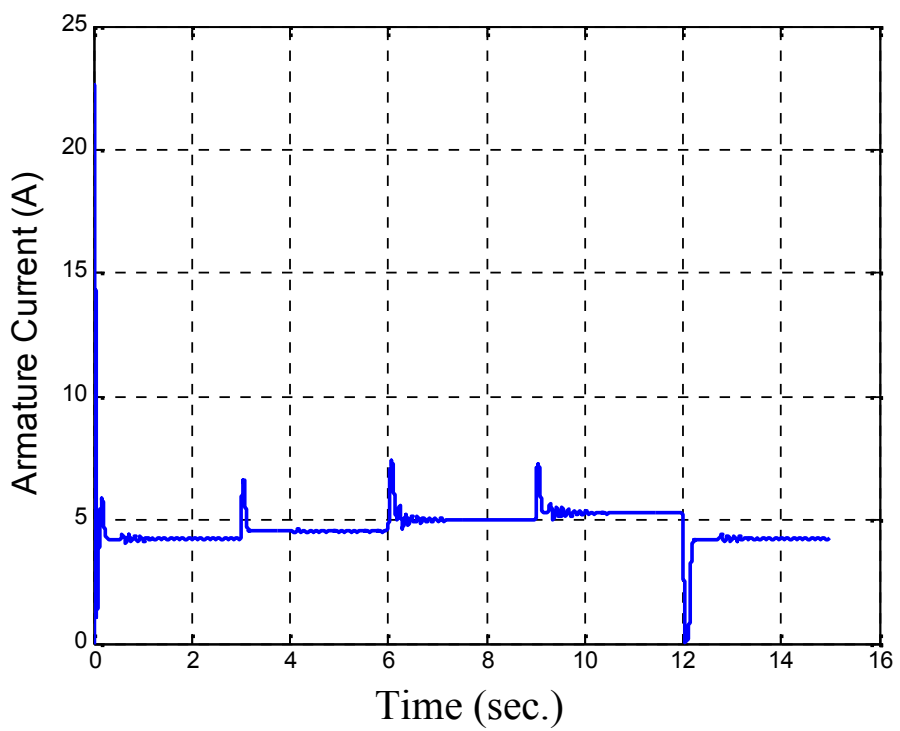

(c)

1. Figure (3) (a) speed (b) average terminal output voltage and (c) armature current responses of the separately excited DC motor in the forward motoring mode.

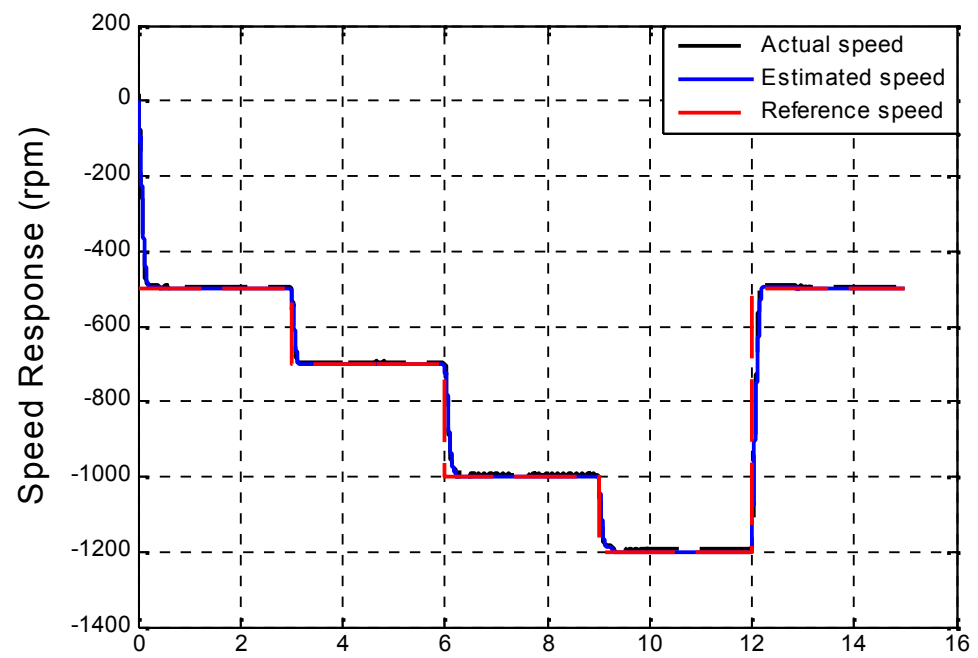

(a)

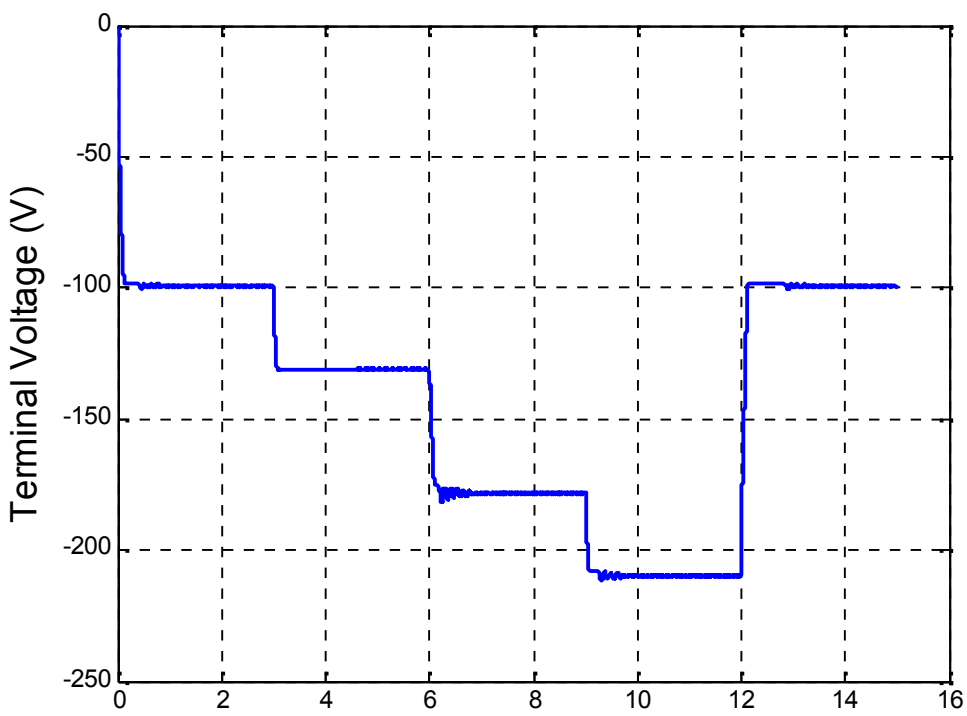

(b) 


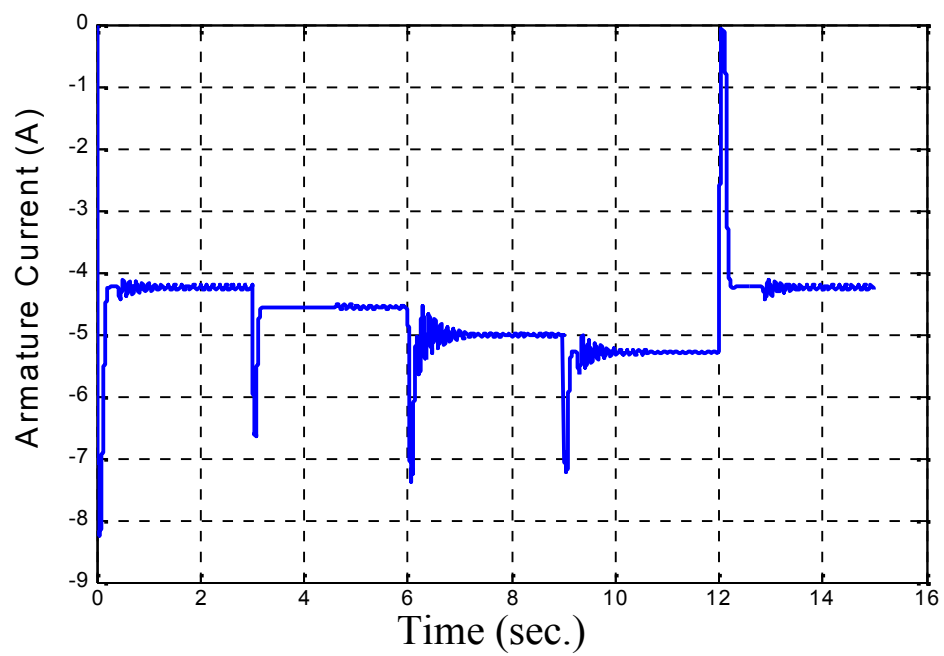

(c)

2. Figure (4) (a) speed (b) average terminal output voltage and (c) armature current responses of the separately excited DC motor in the reverse motoring mode.

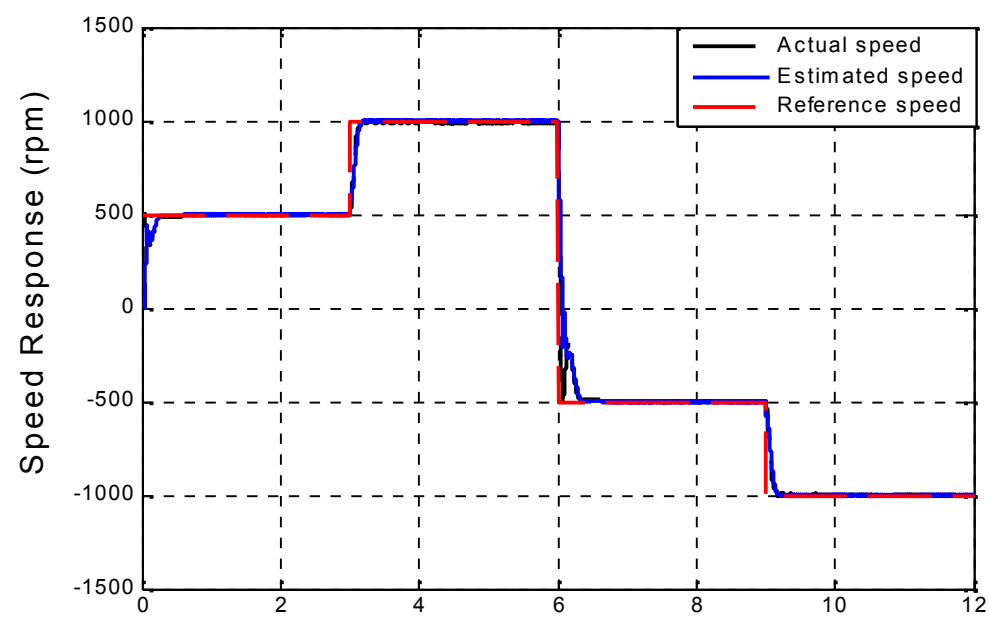

(a)

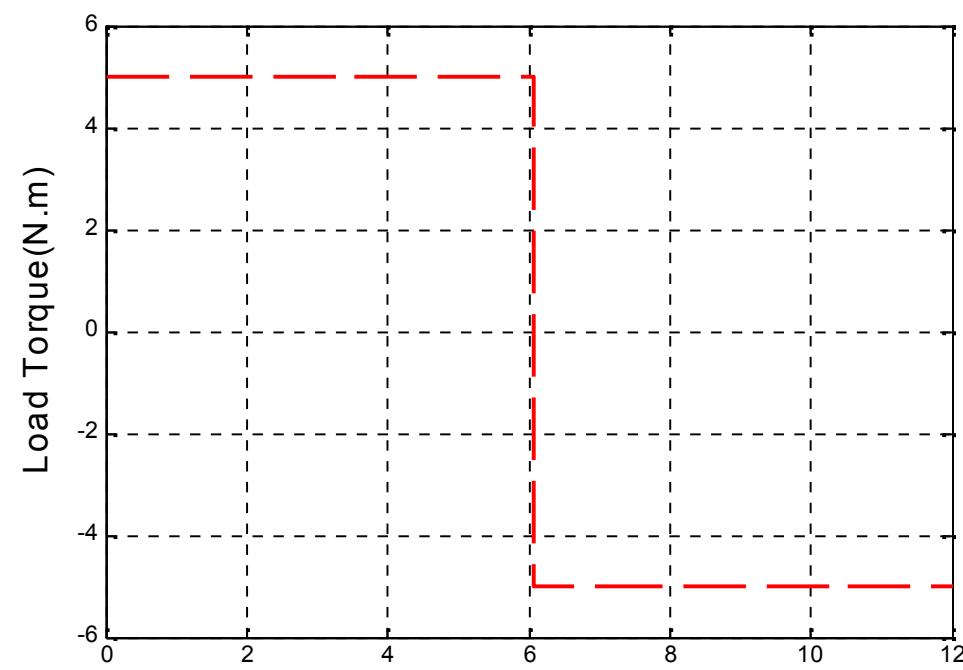

Time (sec.)

(b)

3. Figure (5) Speed and load torque responses of the separately excited DC motor in the forward and reverse motoring modes. 


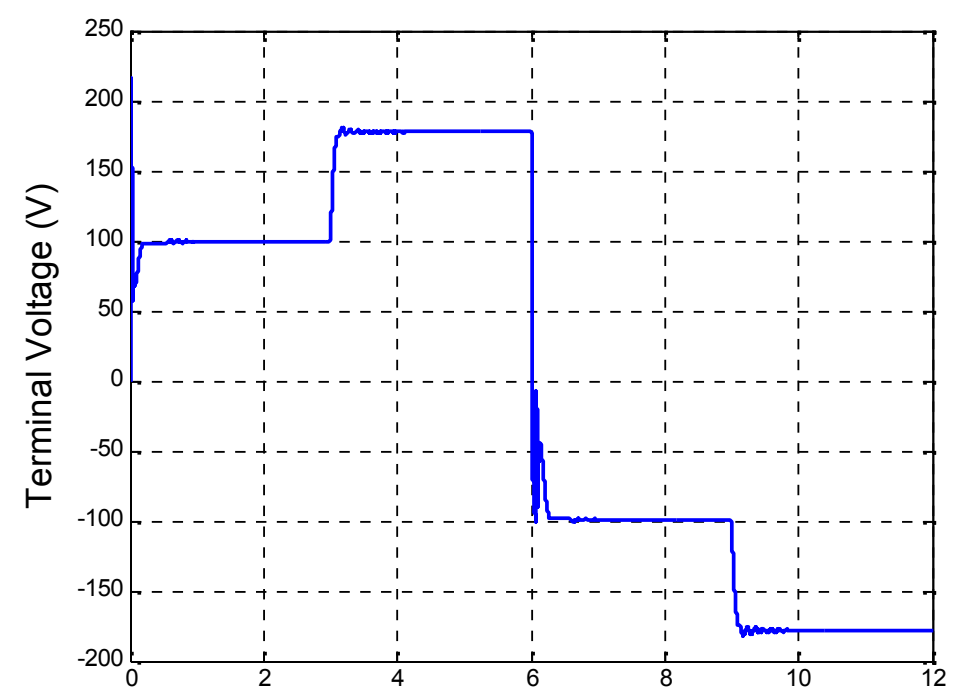

(a)

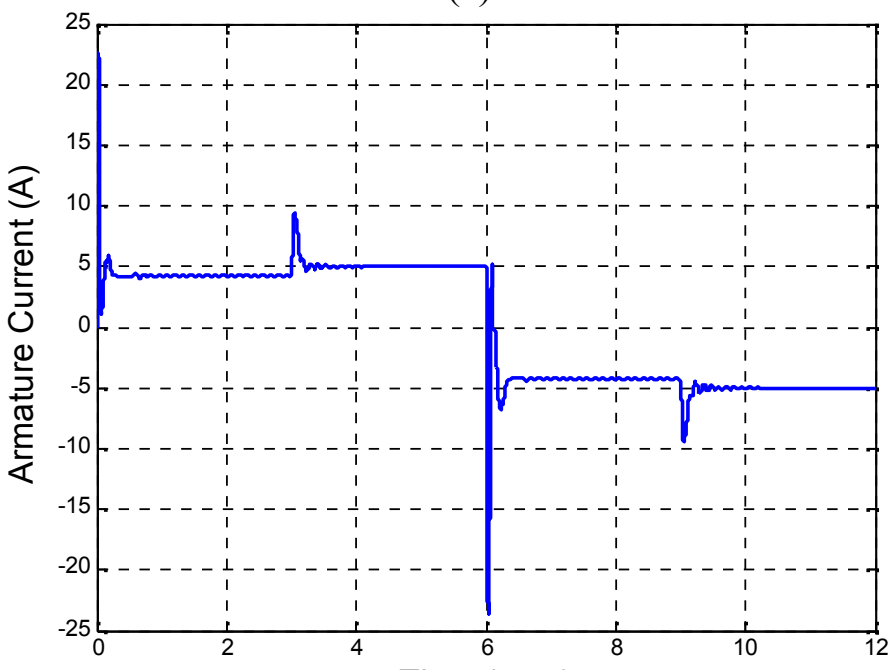

(b)

4. Figure (6) Average terminal voltage and armature current responses of the separately excited DC motor in the forward and reverse motoring modes.

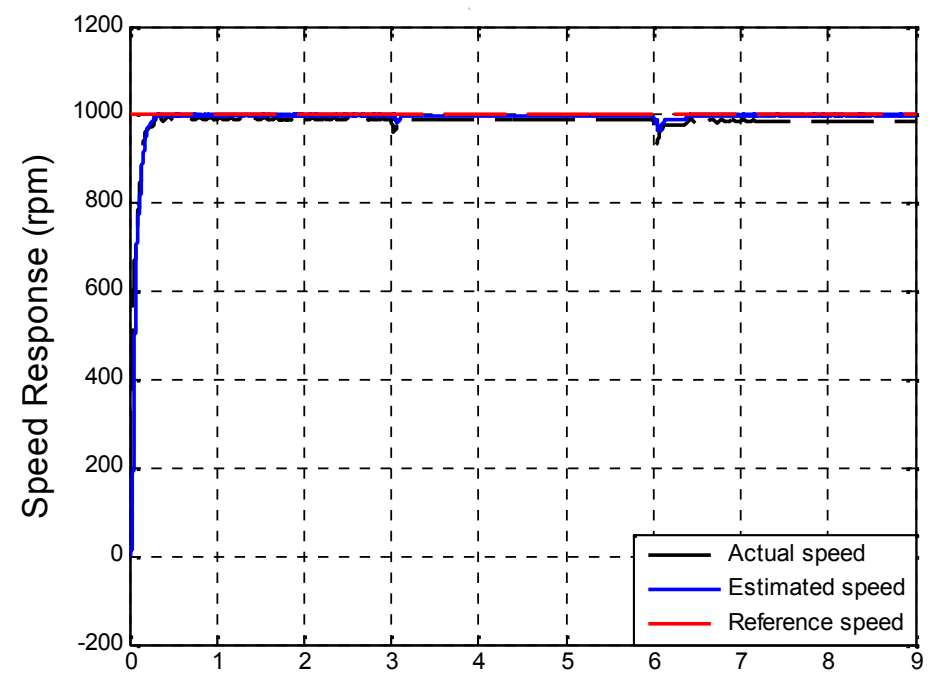

(a) 


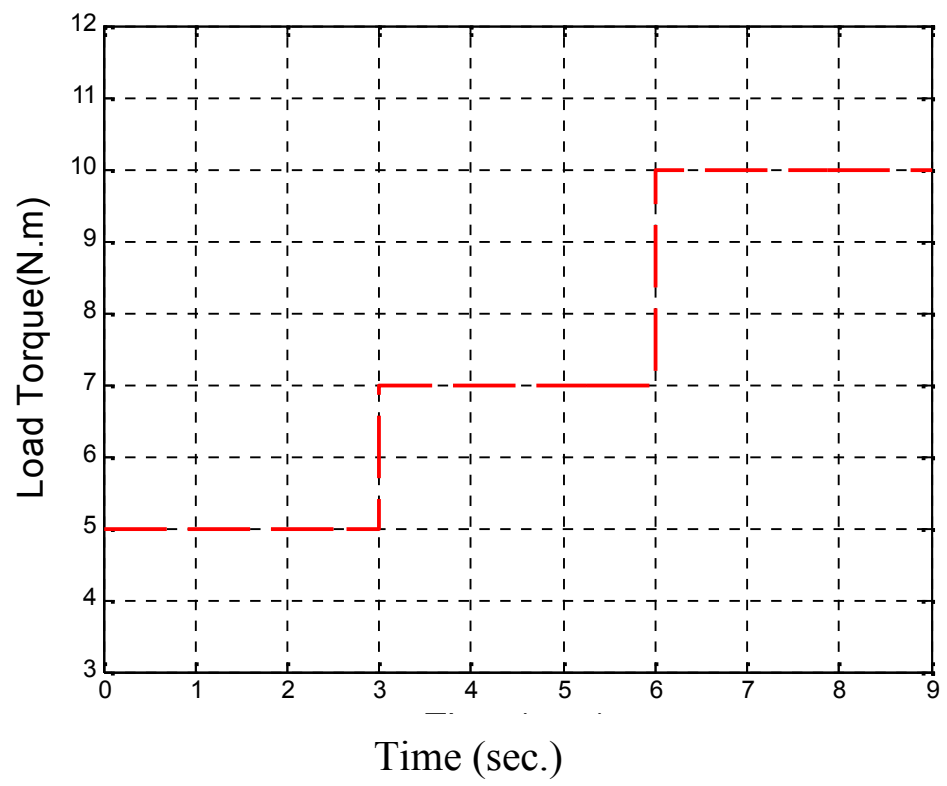

(b)

6. Figure (7) Speed response of the separately excited DC machine with variable load torque in the forward motoring mode.

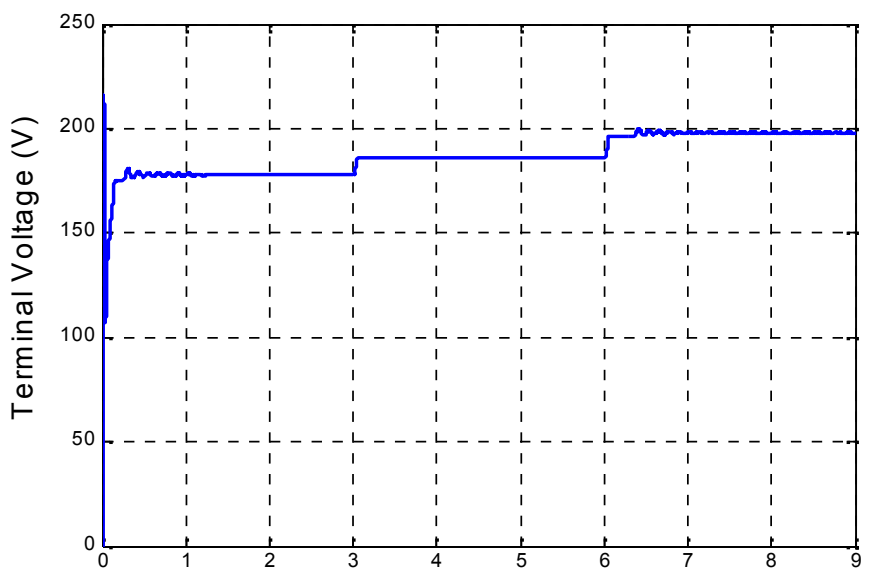

(a)

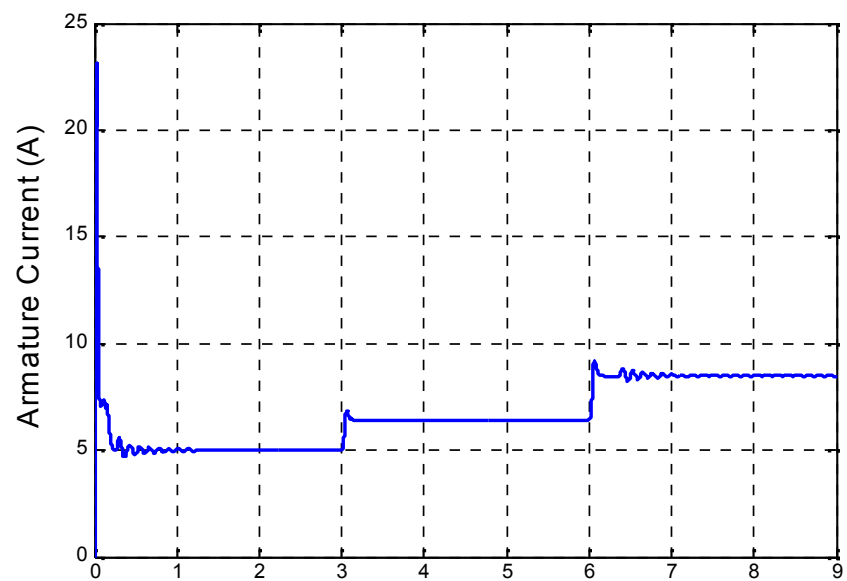

Time (sec.)

(b)

Figure (8) (a) average terminal output voltage and (b) armature current responses of the DC machine with variable load torque in the forward motoring mode. 


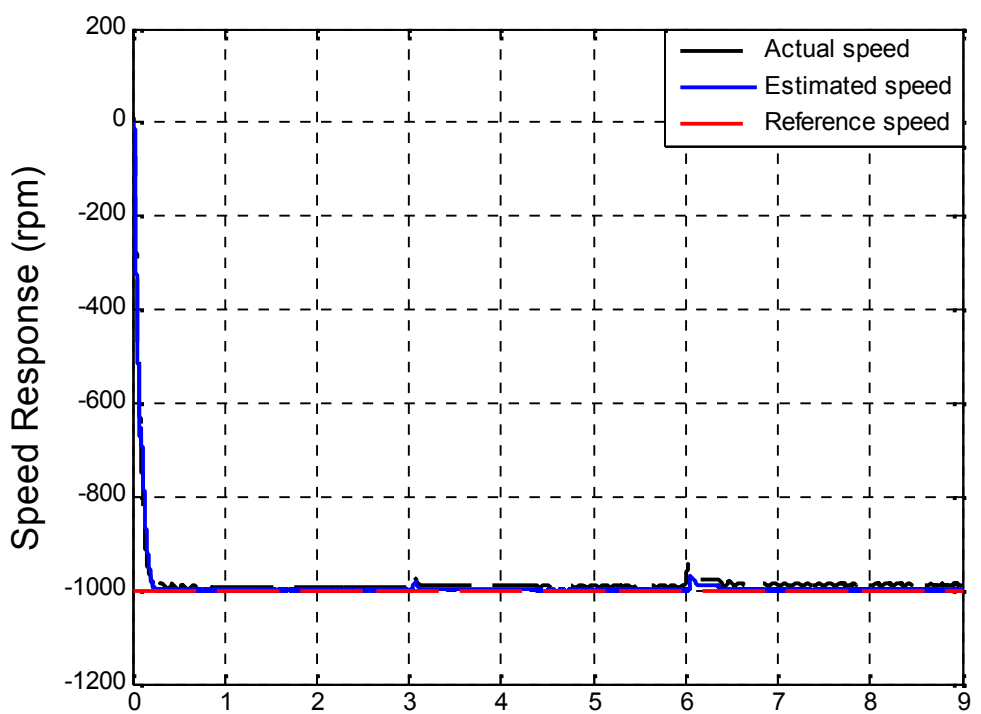

(a)

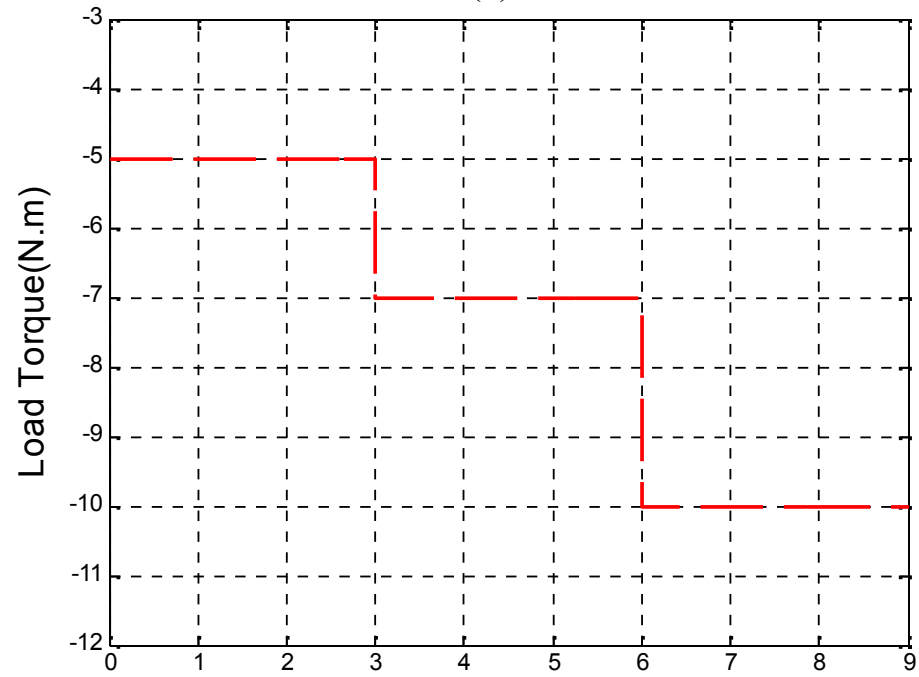

(b)

7. Figure (9) Speed response of the separately excited DC machine with variable load torque in the reverse motoring mode.

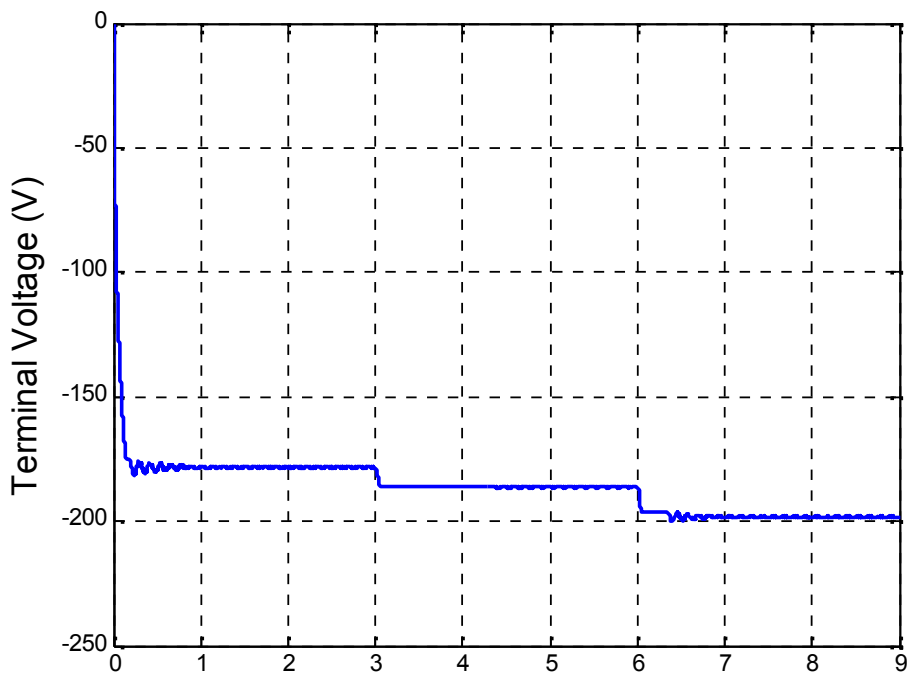

(a) 


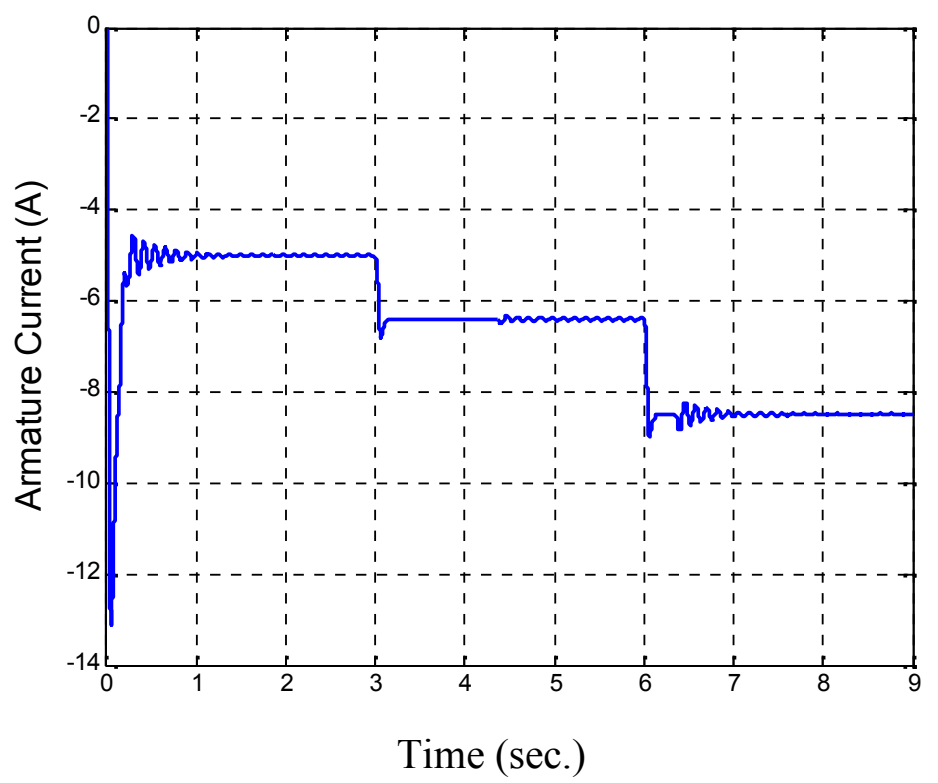

(b)

Figure (10) (a) average terminal output voltage and (b) armature current responses of the DC machine with variable load torque in the reverse motoring mode.

\section{Conclusions}

In this paper, sensorless speed control of a separately excited DC motor has been presented. Estimation speed of the DC motor based on ANN has been done by measuring the chopper instantaneous armature current. Thus, there is no need for tachogenerator feedback. The estimated speed is compared with the reference speed and the result is applied to the PI controller to provide robust speed control of the DC drive. The speed of the DC motor has been controlled in forward and reverse motoring modes. The simulation results illustrate that the ANN is able to estimate the motor speed at constant and variable load torque in both motoring modes. Also show the robustness of the sensorless speed controller to the fluctuation of the estimated speed and load torque variations.

\section{Appendix (Separately Excited DC Machine Data)}

\begin{tabular}{|l|l|}
\hline Voltage Sources $\left(V_{t}\right.$ and $\left.V_{f}\right)=220(\mathrm{~V})$ & Electrical Power $=2 \mathrm{k}(\mathrm{w})$ \\
\hline Armature Current $\left(\mathrm{I}_{\mathrm{a}}\right)=12(\mathrm{~A})$ & Mechanical Torque $=13.64(\mathrm{~N} . \mathrm{m})$ \\
\hline Rate Speed $(\mathrm{n})=1400(\mathrm{rpm})$ & Field Resistance $\left(\mathrm{R}_{\mathrm{f}}\right)=250(\Omega)$ \\
\hline Moment of Inertia $(\mathrm{J})=0.012\left(\mathrm{Kg} . \mathrm{m}^{2}\right)$ & Field Inductance $\left(\mathrm{L}_{\mathrm{f}}\right)=50(\mathrm{H})$ \\
\hline Friction Coefficient $(\mathrm{B})=0.024(\mathrm{~N} . \mathrm{m} . \mathrm{s})$. & Mutual Inductance $\left(\mathrm{L}_{\mathrm{af}}\right)=1.6(\mathrm{H})$ \\
\hline Armature Resistance $\left(\mathrm{R}_{\mathrm{a}}\right)=5(\Omega)$ & \\
\hline
\end{tabular}

\section{References}

1. A. H. Obeid Ahmed, "High Performance Speed Control of Direct Current Motors Using Adaptive Inverse Control", WSEAS TRANSACTIONS on SYSTEMS and CONTROL, Issue 2, Volume 7, page: 54-63, April, 2012.

2. G. Gyorok, J. Lakner and M. Mako, "Predictive Sensorless D.C. Motor Control", Carpathian Journal of Electronic and Computer Engineering CJECE, Volume 3, No.1, 2010.

3. F. Farkas and S. Halász, "Adaptive Fuzzy Speed Controller for DC Drives Using Low Precision Shaft Encoder”, EDPE'99, High Tatras, Slovakia, page: 17-22, 1999. 
4. M. George, "Speed Control of Separately Excited DC Motor", American Journal of Applied Sciences 5 (3), page:227-233, 2008.

5. W. I. Hameed and K. A. Mohamad, "Speed Control of Separately Excited DC Motor using Fuzzy Neural Model Reference Controller", International Journal of Instrumentation and Control Systems (IJICS), Volume 2, No.4, page:27-39, October, 2012.

6. A. L. Hashmia SH. Dakheel, "Speed Control of Separately Exited DC Motor using Artificial Neural Network", Journal of Engineering and Development, Volume 16, No.4, pages: 349-362, December 2012.

7. M. H. Rashid, "Power Electronics: Circuit, Devices and Applications", New Delhi (Prentice-Hall of India Private Limited), second edition, 1994. 